\title{
What we (do not) know about mammal coronavirus and general virus? Using bibliometric information to identify neglected taxonomic groups and potential viral reservoirs of zoonotic importance
}

\author{
Rhewter Nunes (ii) 1*, Renata de Oliveira Dias (iD) 1, Flávia Melo Rodrigues (ii) 2,3, Mariana \\ Pires de Campos Telles (D) 1,2 \\ ${ }^{1}$ Laboratório de Genética e Biodiversidade (LGBio), Instituto de Ciências Biológicas, Universidade Federal de Goiás (UFG), \\ GO, Brasil. Av. Esperança, s/n - Chácaras de Recreio Samambaia, 74690-900, Goiânia, GO, Brazil. \\ 2 Escola de Ciências Agrárias e Biológicas, Pontifícia Universidade Católica de Goiás (PUC Goiás), GO, Brasil. Av. Engler, \\ 286-316 - Jardim Mariliza, 74885-460, Goiânia, GO, Brazil. \\ ${ }^{3}$ Instituto Acadêmico de Ciências da Saúde e de Biológicas, Universidade Estadual de Goiás (UEG), GO, Brasil. Br 153 \\ Quadra Área Km 99 Zona Rural, 75132-903, Anápolis, GO, Brazil.
}

*Corresponding author. E-mail: rhewter@gmail.com

\begin{abstract}
The COVID-19 pandemic is currently advancing in the world and has killed more people than other recent coronavirus outbreaks like SARS and MERS together. Coronaviruses known to infect humans were all associated to mammal sources, with different species acting as both natural and/or intermediate hosts of these viruses. Although the zoonotic origin of human coronaviruses is well accepted, a great number of mammal species were not yet investigated as their potential to carry these viruses. This work aimed to provide an overview of the current state of scientific knowledge about what are the mammal groups well known to be associated to coronaviruses and other viruses and what are the most neglected groups in these studies. Here we analyze the production of scientific publications about these and other viruses in association with the 29 taxonomic orders of the Mammalia class. Our results highlighted that most of these taxonomic orders have been little studied or completely unexplored in researches with this focus, with only six orders accumulating more than $99 \%$ of the articles on coronaviruses in mammals. Ten mammal groups were not found in any scientific publication in association with coronaviruses, with four of them not found even in works mentioning any type of viruses. These results reinforce the importance of identify all the natural and intermediate hosts for viruses to improve monitoring of potential zoonosis and reduce the chances of new disease outbreaks.
\end{abstract}

Keywords: COVID-19, Bibliometric indicators, Epidemic prevention, SARS-CoV-2, Wildlife zoonoses.

DOI: http://dx.doi.org/10.33837/msj.v3i1.1240

Received May 25, 2020. Accepted August 12, 2020.

Associate editor: André Gadelha

\section{INTRODUCTION}

Coronavirus is a category of viruses with singlestranded and positive-sense RNA genome that can cause respiratory diseases in mammals and birds (Marra et al., 2003, Masters, 2006, Schoeman \& Fielding, 2019). Infections occur mainly through the respiratory tract but can also affect the digestive system of different animals, including some Artiodactyla, such as cattle and pigs (Chu et al., 2014, Pensaert \& Callebaut, 1974). These infections can show

\section{Copyright $@$ The Author(s).}

This is an open-access paper published by the Instituto Federal Goiano, Urutai - GO, Brazil. All rights reserved. It is distributed under the terms of the Creative Commons Attribution 4.0 International License. mild, flu-like symptoms, or even lead to death (Guan et al., 2003). Currently, seven strains of coronavirus are known to infect humans and they all evolved from coronaviruses from other mammals (Azhar et al., 2014, $\mathrm{Hu}, \mathrm{Ge}$, Wang, \& Shi, 2015). The three best-known strains, due to their potential to cause severe acute respiratory syndrome, are SARS-CoV (SARS, Severe Acute Respiratory Syndrome), MERS-CoV (MERS, Middle East Respiratory Syndrome), and SARS-CoV-2 (COVID-19, Coronavirus disease 2019) (Haagmans et al., 2014, Lipsitch, Swerdlow, \& Finelli, 2020, Marra et al., 2003). Currently, the world is experiencing a pandemic of COVID-19 with a death toll that already surpassed the SARS and MERS epidemics together, although the significantly lower lethality rate of these new disease (World Health Organization, 2019). It is known that some animals can serve as viral reservoirs and/or potentially be the vectors for human infections (Li et al., 2005). In the case of coronavirus, mammals 
are the animals of greatest zoonotic importance with infections in humans being related to transmissions from domestic and wildlife species. As wildlife trade activities continue in many parts of the world, new epidemics may arise in the future (Prevent and predict, 2020).

The reduction in the chances of a new coronavirus epidemic outbreaks will be more efficient if the prevention starts on its source, with strategies to reduce the wildlife trade, investigating the virus natural hosts and developing efficient monitoring programs. As scientific information is crucial to know animals that are potential reservoirs and vectors, we evaluated the current state of production of scientific knowledge with regard to coronaviruses and other viruses infecting mammals. This work aimed to provide an overview of the current state of scientific knowledge about what are the mammal groups well known to be associated to coronaviruses and other viruses and what are the most neglected groups in these studies. Our main goal is to reveal which orders of mammals are best studied in association to viruses and which of them are neglected. These results can be useful in listing priority mammal groups to be analyzed in further studies aiming to detect natural hosts of viruses, which can be potential sources of new disease outbreaks.

\section{MATERIAL AND METHODS}

We retrieved information about total scientific production on mammals in association with coronaviruses and all viruses using Web of Science (http://apps.webofknowledge.com/). We used search terms related to 29 orders in the class of mammals based on the Integrated Taxonomic Information System (https://www.itis.gov/). The following nomenclature was used for each order were: Afrosoricida (Stanhope, 1998), Artiodactyla (Owen, 1848), Carnivora (Bowdich, 1821), Cetacea (Brisson, 1762), Chiroptera (Blumenbach, 1779), Cingulata (Illiger, 1811), Dasyuromorphia (Gill, 1872), Dermoptera (Illiger, 1811), Didelphimorphia (Gill, 1872), Diprotodontia (Owen, 1866), Erinaceomorpha (Gregory, 1910), Hyracoidea (Huxley, 1869), Lagomorpha (Brandt, 1855), Macroscelidea (Butler, 1956), Microbiotheria (Ameghino, 1889), Monotremata (Bonaparte, 1837), Notoryctemorphia (Kirsch in Hunsaker, 1977), Paucituberculata (Ameghino, 1894), Peramelemorphia (Ameghino, 1889), Perissodactyla (Owen, 1848), Pholidota (Weber, 1904), Pilosa (Flower, 1883), Primates (Linnaeus, 1758), Proboscidea (Illiger, 1811), Rodentia (Bowdich, 1821), Scandentia (Wagner, 1855), Sirenia (Illiger, 1811), Soricomorpha (Gregory, 1910) and Tubulidentata (Huxley, 1872). When available on the Integrated Taxonomic Information System, the synonyms and English common names were used to complement the set of search terms using the search operator "OR". Searches about coronaviruses and all viruses were performed independently. In order to retrieve papers related to all types of viruses (including coronaviruses), the words "virus OR viral" were added to search terms whereas to retrieve papers related to coronavirus, the words "coronavirus OR COVID OR SARS OR MERS" were added to the search term. We also collected and plot the scientific production data by year for the top 6 orders in the number of viral associated articles in the time interval from the year 2000 to 2019.

\section{RESULTS AND DISCUSSION}

We found a total of 204,893 articles related to viruses in mammals but only $5.08 \%$ of them $(10,412)$ mentioned coronaviruses. The mammalian orders with the greatest number of studies in association to viruses were: Rodentia ( $n=123,307 ; 60.18 \%)$, Artiodactyla $(n=$ $32,402 ; 15.81 \%)$, Primates $(n=20,080 ; 9.80 \%)$, Carnivora $(n=14,873 ; 7.26 \%)$, Lagomorpha $(n=9,196 ; 4.49 \%)$, and Chiroptera $(n=3,385 ; 1.65 \%)$ (Figure 1A). Together, six of the 29 orders represent $99.19 \%$ of the total scientific production on all types of viruses in association to mammals. No articles were identified associating viruses with the orders Microbiotheria, Notoryctemorphia and Paucituberculata (Figure 1A).

Rodentia, Artiodactyla, Carnivora, Chiroptera, Primates and Lagomorpha have been also the most studied orders of mammals in relation to coronavirus $(99,25 \%$ of the total number of articles about coronavirus) and each of them have 5,617 (53.95\%); 1,781 (17.11\%); 1,336 (12.83\%); 739 (7.10\%); 450 $(4.32 \%) ;$ and $411 \quad(3.95 \%)$ published articles, respectively (Figure 1B). No scientific publications associating coronaviruses with the orders Afrosoricida, Dermoptera, Hyracoidea, Macroscelidea, Microbiotheria, Notoryctemorphia, Paucituberculata, Perissodactyla and Tubulidentata were identified. Furthermore, the orders Cingulata, Dasyuromorphia, Didelphimorphia, Diprotodontia, Monotremata, Peramelemorphia, Pholidota, Pilosa, Proboscidea, Scandentia, Sirenia and Soricomorpha presented less than 10 articles related to coronavirus each (Figure 1B).

Comparing the annual distribution of the scientific production of the six most studied orders of mammals about viruses in general and coronavirus, it is possible to observe some temporal patterns in the efforts to produce scientific knowledge on these themes (Figure 2A e 2B). There was a predominance of articles involving the rodent group (rodents) both in studies with viruses in general and within coronavirus group. Scientific publications associating coronaviruses with the Chiroptera order, which includes bats, only started to be published after 2003. Moreover, Chiroptera together with Artiodactyla had a greater increase in scientific publications associated with coronaviruses from 2012. 
A

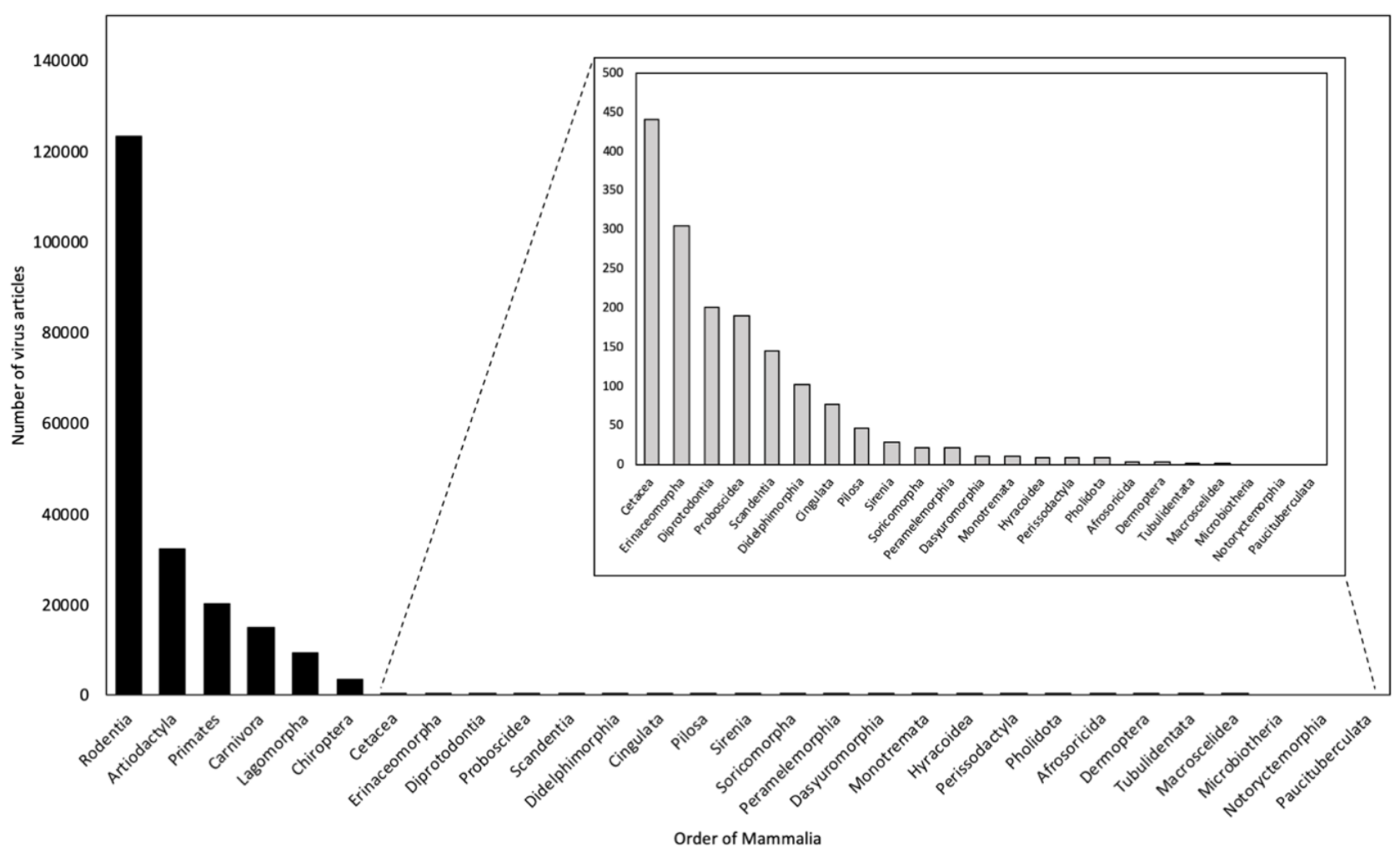

B

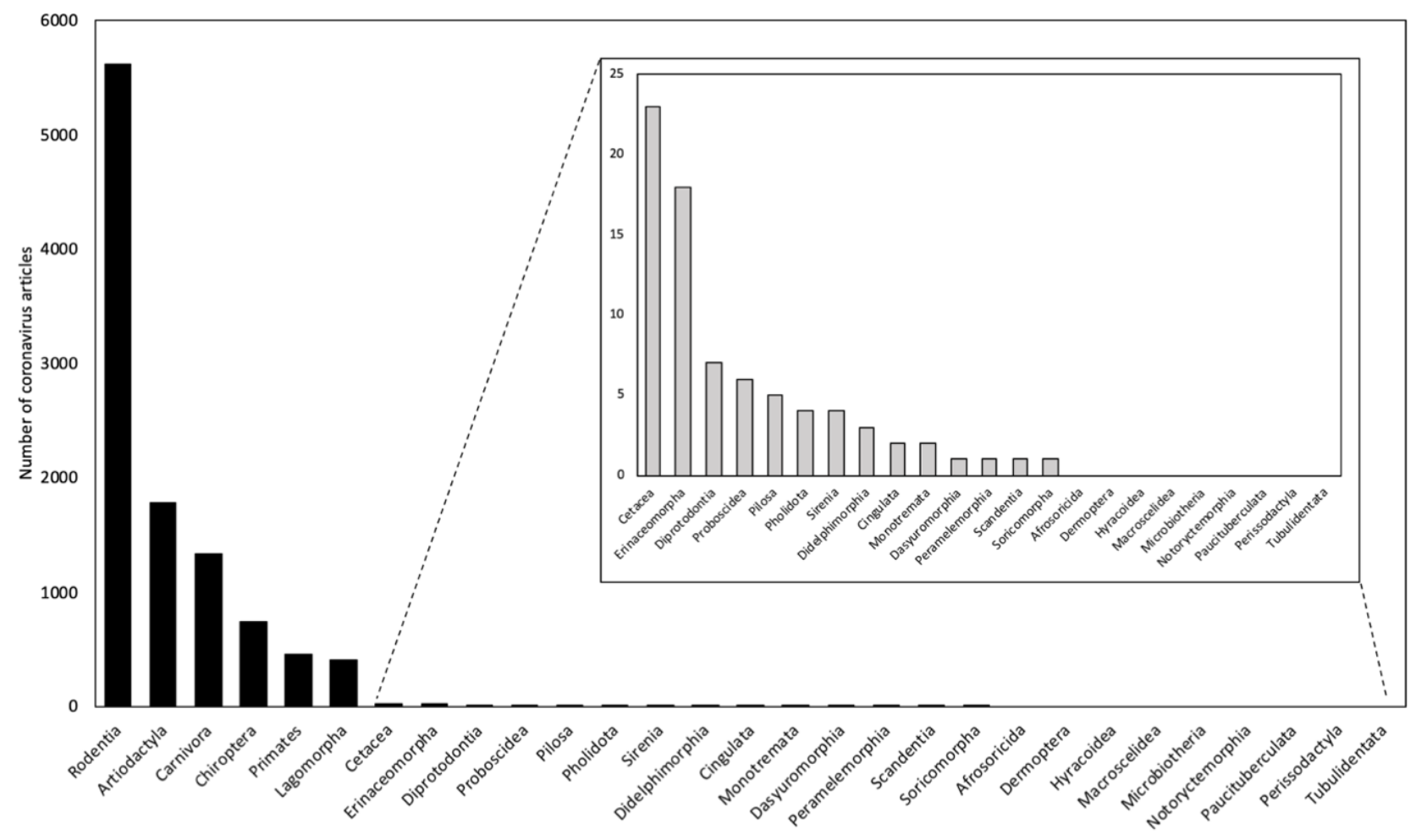

Order of Mammalia

Figure 1. Number of articles in Web of Science about Mammalia orders and: A) virus in general; and B) coronavirus. Zoom in A and B show the orders with that have the fewest article numbers (grey plots). 
A

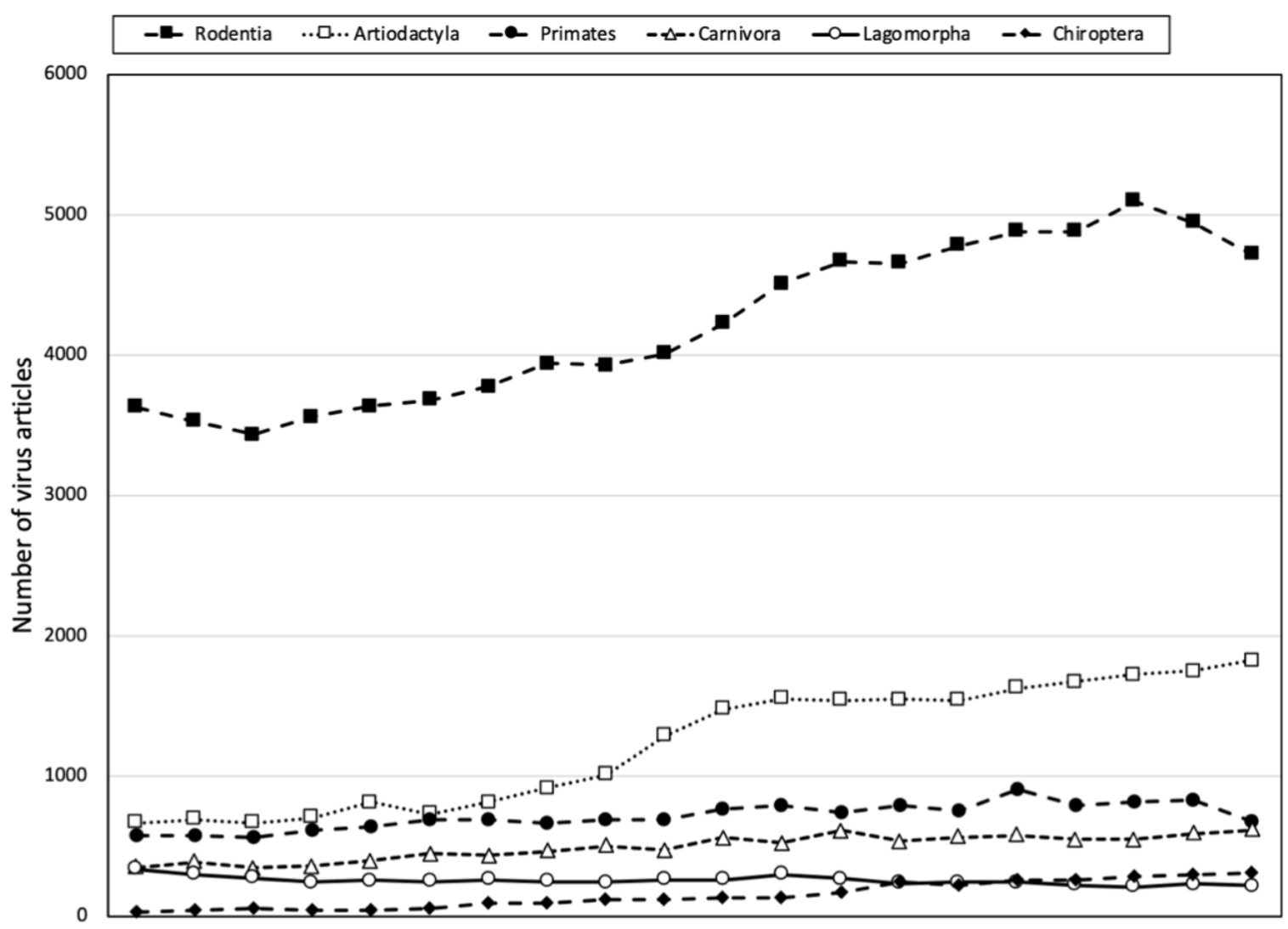

20002001200220032004200520062007200820092010201120122013201420152016201720182019

B

Year of publication

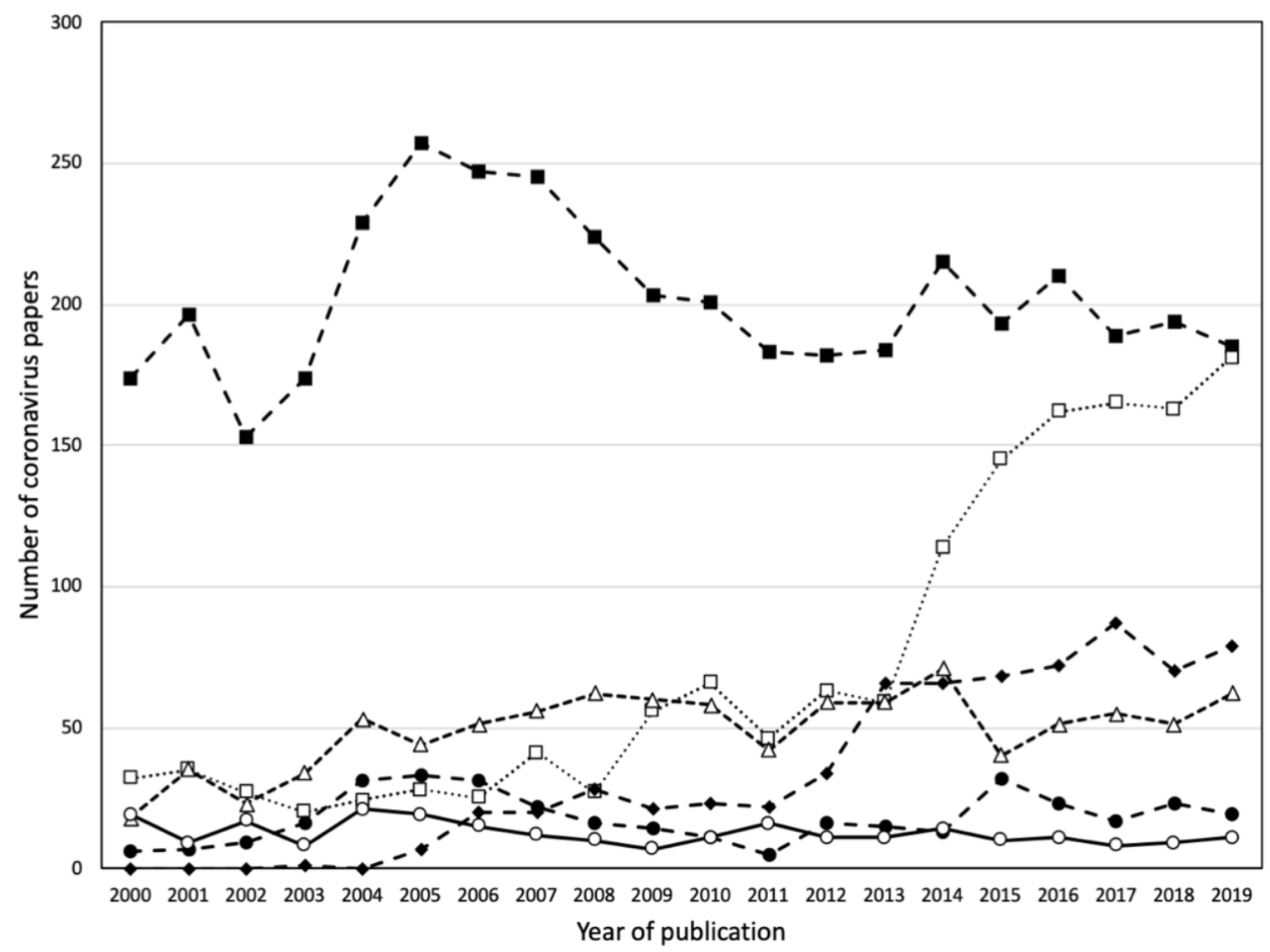

Figure 2. Scientific production by year about the most studied orders of mammals and A) general viruses and B) coronaviruses. 
Our results show that the production of scientific knowledge about coronaviruses and viruses in general in association with mammals was extremely structured. The greater number of published scientific articles for the Rodentia order may be related both to the fact that rats are used as model organisms in experiments and to the fact that these organisms occur in urban areas and are known to be vectors of diseases that infect humans and domestic animals (Gravinatti, Barbosa, Soares, \& Gregori, 2020). In addition, the Rodentia order has the largest number of species among animals with placenta and correspond to $40 \%$ of the total mammal species in the world. Rodentia has 513 genera and 2,552 species (Burgin, Colella, Kahn, \& Upham, 2018). The large number of rodent species and their wide geographical distribution are important factors that may have influenced the number of studies with viruses and coronaviruses present in these animals. In this same sense, Chiroptera is the second most diverse order in number of species among mammals (Burgin, Colella, Kahn, \& Upham, 2018) and presents itself as the sixth most studied group in relation to viruses and the fourth most studied in relation to coronavirus. However, we did not find articles on viruses and coronaviruses in Chiroptera prior to the year 2000, indicating that this type of approach is recent when compared to other mammalian orders.

In the last 20 years, the efforts to study mammal groups, such as the Artiodactyla and Chiroptera, in association with coronaviruses has increased. This growth is probably associated with the SARS epidemics outbreak in 2002 and MERS in 2012 in which bats (SARS and MERS) and camels (MERS) were identified as natural hosts or vectors to the strains that caused the human infections. A slight increase in Carnivora studies was also observed after the 2002 SARS outbreak, which have been associated to market civets zoonotic transmission.

A great number of orders of mammals were neglected both from the point of view of viruses in general, but mainly of coronaviruses studies. This lack of scientific knowledge about viruses in these groups of mammals can leave us at greater vulnerability to new zoonotic epidemic outbreaks, like COVID-19. Many of the mammalian groups neglected in studies with coronaviruses have species trafficked for company (Ex: anteaters - Pilosa) or food (Ex: opossums - Didelphimorphia; and armadillos - Cingulata) (Travis, Watson, \& Tauer, 2011). Other groups cooccur in areas occupied by humans or are known to be geographically close to them (Ex: kangaroos Diprotodontics). Considering the results obtained, we strongly recommend that studies with the groups of mammals that we identified as neglected or poorly studied be carried out in order to optimize strategies for monitoring and preventing new zoonotic disease outbreaks worldwide.

\section{CONCLUSION}

A bibliometric analysis of scientific production related to viruses in general and coronaviruses in mammals has allowed to identify which taxonomic orders have been neglected from a scientific point of view so far. Ignorance of the viruses that affect these groups of animals can lead to serious consequences related to public health, just as we have witnessed the pandemic of COVID-19. We use the indicators of total article production and annual article production to identify groups of mammals that need to have their viruses studied in order to identify and prevent possible outbreaks, endemics and pandemics.

\section{ACKNOWLEDGEMENTS}

This work was developed in the context of the National Institutes for Science and Technology in Ecology, Evolution and Biodiversity Conservation (INCT - EECBio), supported by MCTIC/CNPq (process \#465610/2014-5) and Foundation for Research Support of the State of Goias (FAPEG), in addition to support from PPGS CAPES/FAPEG (Public Call $\# 08 / 2014)$ and National Council for Scientific and Technological Development (CNPq) (Call MCTIC/CNPq \#28/2018, process 435477/2018-8). RN was supported by DTI fellowship from $\mathrm{CNPq}$ and MPCT was supported by productivity fellowship from CNPq. RN is a postdoctoral fellow linked to the Graduate Program in Genetics and Molecular Biology (PPGBM) at the Federal University of Goiás and thanks the support for carrying out this work.

\section{CONFLICT OF INTEREST}

The authors declare no conflict of interest.

\section{REFERENCES}

Azhar, E. I., El-Kafrawy, S. A., Farraj, S. A., Hassan, A. M., Al-Saeed, M. S., Hashem, A. M., \& Madani, T. A. (2014). Evidence for camel-to-human transmission of MERS coronavirus. New England Journal of Medicine, 370(26), 2499-2505. https://doi.org/10.1056/NEJMoa1401505

Burgin, C. J., Colella, J. P., Kahn, P. L., \& Upham, N. S. (2018). How many species of mammals are there? Journal of Mammalogy, 99(1), 1-14. https://doi.org/10.1093/jmammal/gyx147

Chu, D. K. W., Poon, L. L. M., Gomaa, M. M., Shehata, M. M., Perera, R. A. P. M., Zeid, D. A., ... Kayali, G. (2014). MERS coronaviruses in dromedary camels, Egypt. Emerging Infectious Diseases, 20(6), 1049-1053. https://doi.org/10.3201/eid2006.140299

Gravinatti, M. L., Barbosa, C. M., Soares, R. M., \& Gregori, F. (2020). Synanthropic rodents as virus reservoirs and transmitters. Revista Da Sociedade Brasileira de Medicina Tropical, 53, 1-11. https://doi.org/10.1590/0037-8682-0486-2019

Guan, Y., Zheng, B. J., He, Y. Q., Liu, X. L., Zhuang, Z. X., Cheung, C. L., ... Poon, L. L. M. (2003). Isolation and characterization of viruses related to the SARS coronavirus from animals in Southern China. Science, 302(5643), 276-278. https://doi.org/10.1126/science.1087139

Haagmans, B. L., Al Dhahiry, S. H. S., Reusken, C. B. E. M., Raj, V. S., 
Galiano, M., Myers, R., ... Koopmans, M. P. G. (2014). Middle East respiratory syndrome coronavirus in dromedary camels: An outbreak investigation. The Lancet Infectious Diseases, 14(2), 140-145. https:// doi.org/10.1016/S1473-3099(13)70690-X

Hu, B., Ge, X., Wang, L. F., \& Shi, Z. (2015). Bat origin of human coronaviruses Coronaviruses: Emerging and re-emerging pathogens in humans and animals Susanna Lau Positivestrand RNA viruses. Virology Journal, 12(1), 1-10. https://doi.org/10.1186/s12985-015-0422-1

Li, W., Shi, Z., Yu, M., Ren, W., Smith, C., Epstein, J. H., ... Wang, L. F. (2005). Bats are natural reservoirs of SARS-like coronaviruses. Science, 310(5748), 676-679. https://doi.org/10.1126/science.1118391

Lipsitch, M., Swerdlow, D. L., \& Finelli, L. (2020). Defining the Epidemiology of Covid-19 - Studies Needed. The New England Journal of Medicine, 382(13), 1194-1196. https:// doi.org/10.1056/NEJMp2002125

Marra, M. A., Jones, S. J. M., Astell, C. R., Holt, R. A., Brooks-wilson, A., Butterfield, Y. S. N., ... Roper, R. L. (2003). The Genome Sequence of the SARS-Associated Coronavirus, 300, 13991405.

Masters, P. S. (2006). The Molecular Biology of Coronaviruses. Advances in Virus Research, 65, 193-292. https:// doi.org/10.1016/S0065-3527(06)66005-3

Pensaert, M. B., \& Callebaut, P. E. (1974). Characteristics of a coronavirus causing vomition and wasting in pigs. Archiv Fur Die Gesamte Virus forschung, 44(1), 35-50. https://doi.org/10.1007/BF01242179

Prevent and predict. (2020). Nature Ecology \& Evolution, 4(3), 283-283. https:// doi.org/10.1038/s41559-020-1150-5

Schoeman, D., \& Fielding, B. C. (2019). Coronavirus envelope protein: Current knowledge. Virology Journal, 16(1), 1-22. https:// doi.org/10.1186/s12985-019-1182-0

Travis, D. a, Watson, R. P., \& Tauer, A. (2011). The spread of pathogens through trade in wildlife. Rev. Sci. Tech., 30(1), 219239.

World Health Organization (2020). Coronavirus disease 2019 (COVID-19): situation report, 72 .

To cite this paper:

Nunes, R., Dias, R. O., Rodrigues, F. M., \& Telles, M. P. C. (2020) What we (do not) know about mammal coronavirus and general virus? Using bibliometric information to identify neglected taxonomic groups and potential viral reservoirs of zoonotic importance. Multi-Science Journal, 3(1): 53-58. DOI: http://dx.doi.org/10.33837/msj.v3i1.1240 